\title{
Resilience in Organizations and Societies: The State of the Art and Three Organizing Principles for Moving Forward
}

Maria Laura Frigotto, Mitchell Young, and Rómulo Pinheiro

\section{The Centrality of Resilience Today}

Recent social, political, economic and organizational events (the global financial crisis, the rise of populism, migration, climate change, the COVID-19 pandemic, etc.) have renewed policy and scholarly interest in resilience as a desired feature of modern societal systems. Thus,

\section{L. Frigotto $(\otimes)$}

Department of Economics and Management, University of Trento, Trento, Italy e-mail: marialaura.frigotto@unitn.it

M. Young

Department of European Studies, Institute of International Studies, FSV, Charles University, Prague, Czech Republic

e-mail: young@fsv.cuni.cz

R. Pinheiro

Department of Political Science and Management, University of Agder, Kristiansand, Norway

e-mail: romulo.m.pinheiro@uia.no

(C) The Author(s) 2022

R. Pinheiro et al. (eds.), Towards Resilient Organizations and Societies, Public Sector Organizations, https://doi.org/10.1007/978-3-030-82072-5_1 
resilience has become central in various social science domains (Fisher et al., 2019; Linnenluecke, 2017; Williams et al., 2017) and constitutes a suitable concept for tackling contexts or situations that appear to be increasingly volatile, uncertain, complex and ambiguous (VUCA). Resilience emerged out of a general discontent with linear and reductionist perspectives in science and provides a more holistic approach to understanding an increasingly interconnected, dynamic and complex world. So-called 'wicked problems' (cf. Head, 2008) or 'grand challenges' (United Nations ${ }^{1}$ ) - such as climate change, poverty and racial and gender equality-are thought to be impossible to address without resorting to a more holistic view that brings together different disciplinary, theoretical and conceptual perspectives and explores both the social entities in question and the nested systems and interrelationships in which they are embedded. Extant research on resilience from different research perspectives has ascertained that the phenomenon is multifaceted (e.g. Giustiniano et al., 2018; Ruth \& Goessling-Reisemann, 2019; Walker \& Salt, 2006), making multidisciplinarity both essential to addressing resilience as a phenomenon and a theory.

Resilience has been the target of numerous studies in recent years, and it has gathered momentum (Manyena, 2006). A quick google scholar search (27.05.2020) of the term 'resilience' in the period 2000-2020 yielded 1.27 million results, $97 \%$ of which occurred in the last decade alone, attesting to the popularity of the concept/phenomena among scientists. Scholars within the fields of environmental studies/science and psychiatry were rather prominent (Table 1.1).

In a recent literature review, Giustiniano et al. (2018, pp. 18-19) identify 20 influential scientific papers on resilience between 1973 and 2017. Twelve belonged to the management/business/administrative sciences literature, while the rest pertained to the fields of psychology, ecology and cybernetics. Bhamra's (2016, p. 17) analysis of the state of the art of resilience studies (108 papers; 1973-2015) identified the following five key perspectives in descending order of importance/number of influential papers: organizational, socio-ecological/community, individual, ecological and supply chain. Behaviour and dynamics were the most prevalent concepts, featuring in the majority $(68 \%)$ of the publications, 'possibly due to theoretical and conceptual features of the concept of resilience

${ }^{1}$ Online at: https://www.un.org/en/sections/issues-depth/global-issues-overview/. 
Table 1.1 Resilience papers (title) by disciplinary domain (2010-2020)

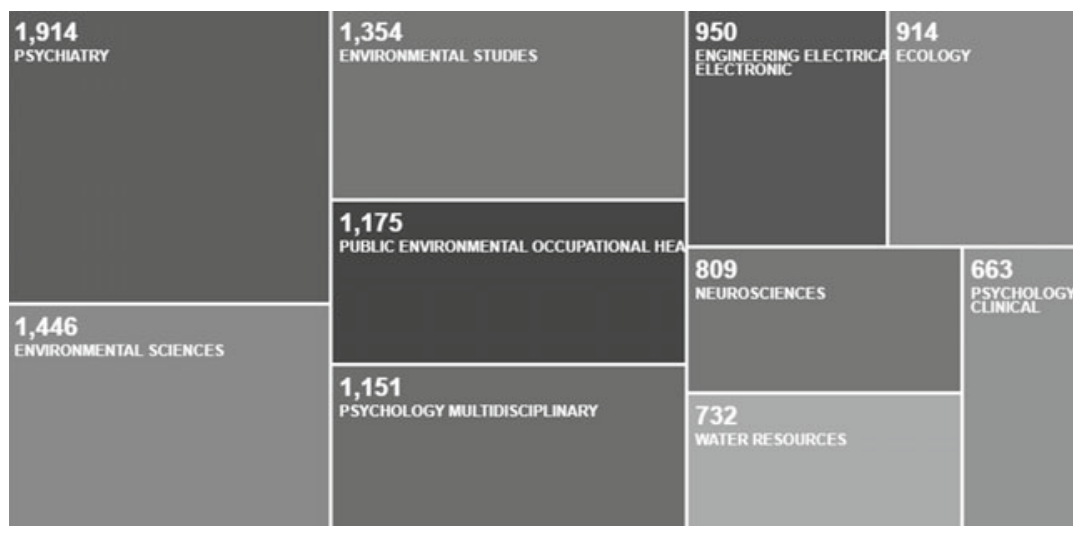

Source Web of Science

being developed' (ibid.). Other topics of significant weight were capability, strategy and performance. This shows that resilience has become highly multidisciplinary, and each discipline has brought forward its own definitions and central bibliographical references. Regarding methodological approaches, theory building and case studies ranked highest, and surveys were the least preferred: 'as the area of resilience-based research has developed, the focus has become increasingly empirically focused' (ibid.), and there is ample room for theoretical elaboration.

\section{The Concept of Resilience}

As a scientific term, 'resilience' originates from engineering and physics and denotes elasticity under pressure (Giustiniano et al., 2018, p. 14). The term derives from the Latin verb salive (climb or jump) and in particular from its extension, resilive, which means to jump back or recoil (Giustiniano et al., 2018; see also Zolli, 2012). Ontologically speaking, resilience thinking pertains to the investigation of complex, interconnected and emergent patterns of relations among entities and their respective sub-entities (Grove, 2018, p. 19). As far as the existing definitions are concerned (Table 1.2), Bhamra (2016) argues that 'regardless of context, the [multifaceted] concept of resilience relates to achieving stability within the functioning of an element or system' (p. 18). 
Table 1.2 Definitions of resilience

\begin{tabular}{|c|c|c|}
\hline Author & Context & Definition \\
\hline Coutu (2002) & Individual & $\begin{array}{l}\text { Resilient individuals possess } \\
\text { three common characteristics: } \\
\text { an acceptance of reality, a } \\
\text { strong belief that life is } \\
\text { meaningful, and the ability } \\
\text { to improvise }\end{array}$ \\
\hline Bruneau et al. (2003) & Disaster management & $\begin{array}{l}\text { The ability of social units to } \\
\text { mitigate hazards, contain the } \\
\text { effects of disasters when they } \\
\text { occur, and carry out recovery } \\
\text { activities that minimise social } \\
\text { disruption and mitigate the } \\
\text { effects of future events }\end{array}$ \\
\hline Bodin and Wiman (2004) & Physical systems & $\begin{array}{l}\text { The speed at which a system } \\
\text { returns to equilibrium after } \\
\text { displacement, irrespective of } \\
\text { oscillations, indicates its } \\
\text { elasticity (resilience) }\end{array}$ \\
\hline McDonald (2006) & Organisational & $\begin{array}{l}\text { Adapting to the requirements } \\
\text { of the environment and } \\
\text { being able to manage the } \\
\text { environment's variability }\end{array}$ \\
\hline Zolli (2012) & Socioecology & $\begin{array}{l}\text { The capacity of a system, } \\
\text { enterprise, or person to } \\
\text { maintain its core purpose and } \\
\text { integrity in the face of } \\
\text { dramatically changed } \\
\text { circumstances }\end{array}$ \\
\hline Walker et al. (2014) & Ecological systems & $\begin{array}{l}\text { The capacity of a system to } \\
\text { withstand a disturbance and } \\
\text { reorganise itself while } \\
\text { retaining function, structure, } \\
\text { identity, and feedback }\end{array}$ \\
\hline $\begin{array}{l}\text { Schaffer and Schneider } \\
(2019)\end{array}$ & Sociotechnical systems & $\begin{array}{l}\text { Protect a system's integrity } \\
\text { by strengthening links to } \\
\text { other systems and tolerating } \\
\text { or even fostering structural } \\
\text { changes }\end{array}$ \\
\hline
\end{tabular}


Table 1.2 (continued)

\begin{tabular}{|c|c|c|}
\hline Author & Context & Definition \\
\hline $\begin{array}{l}\text { European Commission } \\
\text { (2019) }\end{array}$ & Multi-level governance & $\begin{array}{l}\text { The ability to face shocks } \\
\text { and persistent structural } \\
\text { changes in such a way that } \\
\text { societal well-being is } \\
\text { preserved without } \\
\text { compromising the heritage of } \\
\text { future generations }\end{array}$ \\
\hline
\end{tabular}

Sources Adapted from Bhamra et al. (2011, pp. 5379-5380), Zolli (2012, p. 7), Schaffer and Schneider (2019, p. 8), European Commission $(2019)^{2}$

In general, resilience is a property of societal systems, individuals, organizations and organizational fields that enables them to survive despite minor or major disruptions (de Bruijne et al., 2010; Ramanujam \& Roberts, 2018; Walker \& Salt, 2006; Weick et al., 1999; Westrum, 2006; Zolli, 2012). There are two basic perspectives on resilience; they concern: (a) the ability of systems of any kind, including individuals, to bounce back to a state of normality following disruptive and often unexpected events or crises (e.g. how a forest grows again after a fire), and (b) the flexibility to adjust to new, emergent situations without crossing a threshold (e.g. how a forest might adjust to climate change without becoming a quasi-desert).

To some extent, the phenomenon of resilience can be seen as an elaboration of existing theories that frame the interactions between organizations and an increasingly unstable and unpredictable external environment. According to the classic perspective within organizational studies of contingency theory (e.g. Donaldson, 2001) observed outcomes (e.g. striving, survival, etc.) result from a 'fit' or match between environmental imperatives and internal designs or structures. The environment is represented as a list of potential threats that, through the construction of probabilities and scenarios of risk analysis, can be ranked according to risk and uncertainty. This approach allows researchers to focus on the development of effective responses to those categorized situations. A deeper awareness of environmental complexity and volatility, probably due to

2 Online at: https://ec.europa.eu/jrc/en/research/crosscutting-activities/resilience. 
the unprecedented interconnectedness of the world, has recently challenged the possibility of limiting response elaboration to proper actions related to probable contingencies. Systems thinkers have been signalling this interconnectedness since the 1970s (e.g. Meadows et al., 1972), but little attention was paid to indeterminateness until more recent years when researchers started casting doubt on the determinateness of the world and the ability of humans and organizations to understand it-e.g. Weick and Sutcliffe's (2001) 'Expecting the unexpected' and Bazerman and Watkins' (2004) 'Predictable surprises' (Frigotto, 2018). The environment has proved to be hard to classify into precise probable events, because the world is characterized by Knightian 'ignorance', rather than by 'risk' and 'uncertainty' (Knight, 1921). In fact, 'risk' relates to a situation in which probabilities are given, and 'uncertainty' to cases in which states are naturally defined but the translation into probabilities is not; 'ignorance' refers to situations in which states are neither naturally given nor easily constructed (Gilboa \& Schmeidler, 1995, p. 622). The concept of resilience has gained momentum in the last decade, as it can capture this change of perspective. This change also implies a shift in the abilities of individuals, organizations and societies to address the shifts in environment: from the ability to classify it to the ability to resist it, with little importance attributed to the definition of the disturbance, and ideally, independently of the source, form and manifestation of the disturbance.

Although resilience embodies a holistic response that is appropriate to the VUCA: (volatility, uncertainty, complexity and ambiguity) world of today, the way in which it has been imported from engineering and physics to the social sciences has brought to the fore some unaddressed issues that, in our view, diminish the potential of the extant literature to serve as a foundation for a thorough resilience framework. In the social sciences, definitions of 'resilience' (Table 1.2) include the ability of a social entity-i.e. an individual, organization, or system-to respond to and recover from disturbances (Linnenluecke, 2017). The concept has been transferred from the realms of physics and engineering to the realm of social action with a metaphorical meaning and, as noted by Carpenter et al. (2001), this has led to an increasing ambiguity in theoretical understandings, operationalizations and measurements (2001, p. 767). The discourse on resilience has typically focused on one level of analysis at a time and has developed within specific disciplines. For example, books on resilience from an organizational perspective tend to have a narrow rather than a systemic or holistic approach, for instance, focusing on topics such 
as learning and/or the role of leaders (Kayes, 2015; Pirotti, \& Venzin, 2016). Other seminal contributions in the field tend to be more conceptual in nature (Giustiniano et al., 2018) or pay considerable attention to certain subsystems such as ecology (Walker \& Salt, 2006) and sociotechnical systems (Ruth \& Goessling-Reiseman, 2019). Within this landscape of flourishing and diverse literature, this edited volume advances an original perspective on resilience in organizations and societies that combines empirical evidence and theoretical developments at different levels of analysis, from a multiplicity of disciplinary backgrounds and perspectives, as well as, sectors of the economy.

\section{Missing Links on Resilience: Five Key Questions}

In this section, we provide a brief overview of five key questions that need to be addressed in order to reach the next step of resilience theory development and empirical understanding.

In physics, resilience refers to a precise kind of disturbance, namely the ability of a system (typically a material) to absorb energy before breaking down when subject to a dynamic perpendicular force (shock) (Kalpakjian \& Schmid, 2016). This shock is standardized into the Charpy pendulum, which is used to measure the resilience of materials. Resilience is high when a material has a high level of elasticity. For example, the strings of a tennis racket deform due to the impact of a ball and accumulate potential energy that is released during the return stroke. The opposite of resilience is fragility, which is characteristic of materials with little elasticity and that are close to their breaking point. Unlike resistant materials, resilient materials do not oppose shocks until they break, but absorb shocks due to their elastic properties.

Similarly, resilience in the social sciences represents the ability of a social entity - such as an individual, organization, system, or society-to retain its function while responding to adversity. However, this metaphor is responsible for both the appeal and the opaqueness of the concept in the social sciences (Carpenter et al., 2001), as 'ability' and 'adversity' have been variously understood (e.g. Britt et al., 2016), leading many scholars to ask for further theoretical elaboration (Britt et al. 2016; Duchek, 2020; Fisher et al., 2019; Linnenluecke, 2017; Kossek \& Perrigino, 2016; Vanhove et al., 2016). A decade ago, de Bruijne et al. (2010) outlined some of the elements that were lost in translation. This yielded a set of pertinent questions regarding the need for theoretical elaboration, 
which have been echoed by more recent literature reviews (e.g. Duchek, 2020; Fisher et al., 2019; Linnenluecke, 2017; Kossek \& Perrigino, 2016; Ruiz-Martin et al., 2018).

Five questions have remained largely implicit in the understanding of the parallel between materials in physics and individuals, organizations and societies in the social sciences. Here we identify and reframe them to develop three principles that both organize our current understanding of resilience and suggest future directions of research.

First, in the social sciences, resilience has been used in quite a broad way. Following a thorough literature review on existing perspectives, concepts and methodologies, Bhamra (2016, p. 24) contended that it is essential to understand whether resilience is a measure, a feature, a philosophy or a capability', as in the present literature it refers to all of these. Critics of resilience claim that the concept has been adopted too broadly in the social sciences and provocatively ask: 'At this rate, what isn't resilience?' (Roe \& Schulman, 2008, p. 163). To progress with conceptual elaboration, this implies asking: What is the core of resilience? Addressing this question clarifies how the concept of resilience can be characterized and better specified to include different conceptual and analytical manifestations while still allowing for the cross-fertilization of concepts, ideas and best practices across the social sciences.

Second, when we say that resilient social entities reach a final state after facing adversities, how should this final state be understood? Answering this question means clarifying when we can talk about resilience, and when we cannot. Rather than redefining resilience, we aim to define the boundaries and the core of the concept by specifying what 'stable final state' in the social sciences might correspond to the steady states of engineering materials. The fact that a given material finds an equilibrium (i.e. the same state before and after a shock), allows scholars to claim that it is resilient. However, the ways in which individuals, organizations and/or societies respond, recover and return to 'normality' always entails a change - if only because time has passed and experience (learning) has occured. Contrary to physical materials, social systems and the agents that are embedded in them exercise agency, which affects how they adapt to external events. Moreover, it is crucial to clarify whether we can talk of resilience when a 'new normal' is reached in a social system, or if that means that the original system was not resilient and that a new system (with a different state and function) has emerged. So, we ask: what is 
the outcome of resilience? Does the recognition of resilience depend upon this outcome?

Third, how can disturbances or adversity triggers be qualified in the social sciences? Recent studies reviewed the following examples of adversity triggers (Britt et al., 2016; Duchek, 2020; Fisher et al., 2019; Kossek \& Perrigino, 2016; Linnenluecke, 2017; Vanhove et al., 2016): for the individual, the death of a beloved person or a divorce; for organizations, a new technology that challenges extant business value propositions; and for systems, a new political movement that gains ground. In physics, shocks are precisely defined: they have a certain strength and hit from a certain angle (Frigotto, 2020). In the social sciences, the ability to anticipate, resist and respond to adversity is contingent on knowledge of adversity triggers: when they are well-known and well-defined, they can be anticipated or at least a precise response can be prepared that is activated when they occur; when they are poorly-known and ill-defined, understanding them is part of the challenge (cf. Logan, 2009). Some authors refer to this in terms of the expected and the unexpected (e.g. Weick \& Sutcliffe, 2001). While this distinction is intuitive, a more precise elaboration could clarify the impacts of different kinds of adversity and their potential for triggering resilience and its various empirical manifestations.

Fourth, in the social realm, resilience concerns an entity's responses to a shock over time, including before (preparedness), during (recovery) and after (outcome). While a temporal dimension is noticeable in social systems that might take time to show resilience, what some call 'dynamic capability' (Giustiniano et al., 2018, p. 38), others consider a process, as well as, a property and an outcome (Bhamra, 2016) So, the following question arises: does resilience have a temporal deployment upon which it should be observed and assessed as a whole?

Fifth, what is the subject of resilience? In general, we have referred to system resilience as having a generic subject in the social sciences, and other times and more precisely, we have articulated three main levels of analysis, i.e. individual (micro), organization (meso) and society (macro). This plurality of levels at which it can manifest adds a layer of fuzziness to resilience, as in the same setting, a lower level entity can show resilience, while at a higher level there might be none and vice versa. Carpenter et al. (2001, pp. 765-767) claim that it is always necessary to specify resilience in relation to a social system or a level of analysis by asking: 'Resilience of what to what?' In particular, it is necessary to address if there is a correspondence between lower and higher levels of resilience, and if lower 
levels of resilience guarantee higher levels of resilience. This has become crucial for policymakers, institutions and citizens in understanding how resilience can be cultivated, especially after the COVID-19 pandemic (e.g. Giovannini et al., 2020).

These five questions, in our opinion, advance the academic debate by allowing us to frame resilience in light of the dynamic nature and complexity and ambiguity inherent to social systems at multiple levels of analysis. This introduction outlines three organizing elements that serve as a starting point for the theoretical and empirical analyses in the chapters that make up the bulk of this edited volume. We argue that resilience needs to be grounded in both stability and change, given that 'becoming' is a characteristic of social entities. We define resilience in terms of change that maintains a continuity of essence, whether self-assessed by those that dealt with the adversity-and that recognize themselves through change-or exogenously assessed when an observer can detect or identify some form of persistence of identity, processes, mindsets, etc.

\section{Organizing Principles for Resilitence}

Building upon the definitional consistencies and inconsistencies, theoretical missing links and empirical puzzles found in the five questions above, this section introduces three organizing principles for resilience. The first pertains to the core of resilience, which comprises both change and stability. The second principle concerns the novelty profiles of adversity triggers. The third principle regards the temporal deployment of resilience into foresight, mechanisms and outcomes, which take place either before adversities trigger resilience, right after they have occurred and stimulated a response, and/or after they have been addressed. This is followed by a discussion of the temporal, spatial and social scale of resilience, which serves both the advancement of our theoretical understanding and the empirical adoption of resilience.

\section{Stability and Change}

Resilience has generally been used to indicate the ability to absorb shocks with a limited impact on stability and functioning (Linnenluecke, 2017; Roe \& Schulman 2008; Walker \& Salt, 2006; Williams et al., 2017) as well as the ability to recover and learn from the shock (Ramanujam \& Roberts, 2018; Ruiz-Martin et al., 2018). In other words, in various 
definitions and disciplines, resilience entails change from an initial state to a final state via adversity response. Change is, therefore, the first fundamental constituent of resilience.

Change can be conceived of as being necessarily entailed by adversity, because if a system does not change, then one could argue that it never faced the sort of adversity for which resilience is needed. Moreover, if it does not change, then it will probably fail, because adversity does not allow systems to remain unaltered over time. If for some reason a system neither changes nor fails, then we would argue that it does not display resilience, but mere survival. Thus, survival is not the key to resilience. Resilience goes beyond mere survival because it requires that the perseverance of being is characterized by change. Likewise, radical change is incompatible with resilience. In fact, we would not call something that changes completely in order to survive resilient, as it would no longer relate to a previous state or function but to something else entirely.

There have been several attempts to theorize about the degree of change that is included in resilience. Like most definitions, the first and more general attempt held that resilience represents either a process of 'bouncing back' or of 'remaining within a threshold' (Table 1.2); 'passing the threshold' was to be understood as too much change to constitute resilience. From a complex systems perspective, Walker et al. (2004) note that both resilience and adaptability have to do with the dynamics of a system or a closely related set of systems. For them, transformability refers to fundamentally altering the nature of a system, yet the dividing line between 'closely related' and 'fundamentally altered' can be fuzzy and subject to interpretation. Folke et al. (2010, p. 3) argue that resilience builds on adaptability and transformability, as it is 'the capacity to change [also through transformation] in order to maintain the same identity'. In regional science studies, several authors (Boschma, 2015; Hu \& Hassink, 2017; Pike et al., 2010) adopt a distinction between two kinds of change within the context of geographic resilience, 'adaptation' and 'adaptability'; the former relates to maintaining existing economic paths/trajectories or 'exploitation' (March, 1991), while the latter pertains to the creation of new regional growth paths or 'exploration' (March, 1991). In other areas, transformation and transformability are more explicitly mentioned and linked to resilience. The literature on urban ecosystems (e.g. Gotham \& Campanella, 2010) explicitly acknowledges transformability among the various types of change; more recently, 
Satyal et al. (2017) showed how transformative resilience can consist of regional pathways of evolution.

A second fundamental constituent of resilience that mirrors the first is continuity of essence. In all cases, resilience is related to a subject-be it an individual, organization or system-that undergoes some degree of change but, nevertheless, maintains a continuity of essence throughout this evolution. This means that, having changed, either the subject or an external observer can recognize that the same entity is still present following a series of internal and external adversities. Considering both the constituents of resilience together, resilience encompasses both stability and change (Fig. 1.1).

In their conceptual framework aimed at both grounding and triggering a more resilient European society, Manca et al. (2017) proposed a distinction between absorptive, adaptive and transformative capabilities that support resilience. In the field of organizational resilience, Frigotto (2020) specified the following resilience outcomes that result from different levels of change (and as a function of the novelty of adversity triggers): absorptive, adaptive and transformative resilience.

Progressing our theoretical elaboration on the essence of resilience and the different kinds of change that resilience encompasses, we posit the following typology. If we position the combination of stability and change on a continuum where at the extreme ends there are either only stability or only change, resilience concerns only the area in which there is a blend

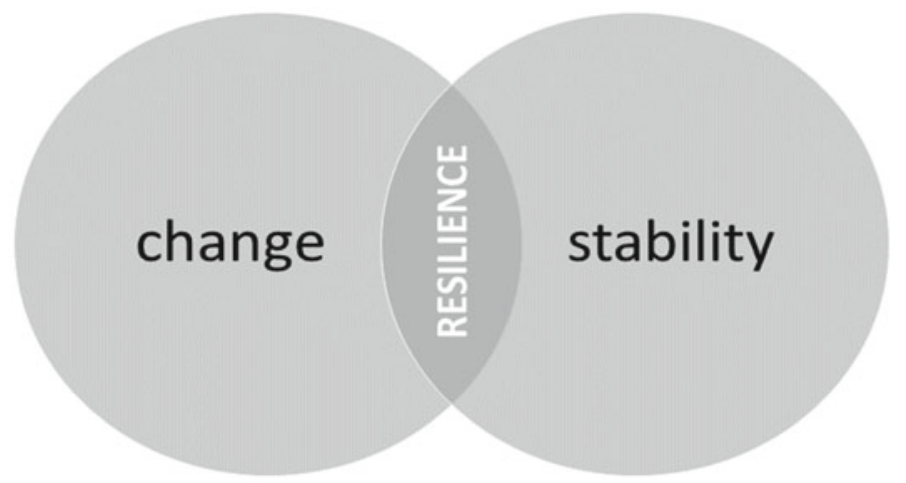

Fig. 1.1 Resilience as the overlap or interplay of stability and change (Source Authors' own) 
of stability and change. Building on Frigotto's work on novelty (2020), it is possible to define different types of resilience, encompassing not only specific outcomes but also changing processes and antecedents. Along this continuum, we can position three main types of resilience (Fig. 1.2).

Absorptive resilience reflects the fundamental stability of a system and concerns the ability to return rapidly and efficiently to the original state; change is limited in that it is both temporary and produces a near-zero impact (Linnenluecke, 2017). Stability is not challenged; it is refreshed or refined by perfecting competencies, and the previous state is restored. Building upon the work of Folke et al. (2010), resilience in this case can be defined as 'absorbability'. In the metaphor provided by the ball-andcup model (de Bruijne et al., 2010, p. 17), the cup represents the stability of the system, whereas the ball represents a social entity that is altered by some force. Resilience is then measured by the time the entity takes to absorb change.

Adaptive resilience includes both stability and change at a consistent level; it refers to a system's ability to produce buffer capacity, withstand shock and maintain function during a transition to a new state. In this case, change is persistent and consistent even though it does not challenge the essence of the social entity. In the ball-and-cup model, this type of resilience is represented by the width of the cup, meaning that while persistent change of functioning is necessary, it is still found in the same context. In real-world situations, resilience is measured by robustness, which is the amount of change that an entity can face within the given context. In Folke et al.'s (2010) terminology, this type of resilience is characterized by both adaptability and flexibility.

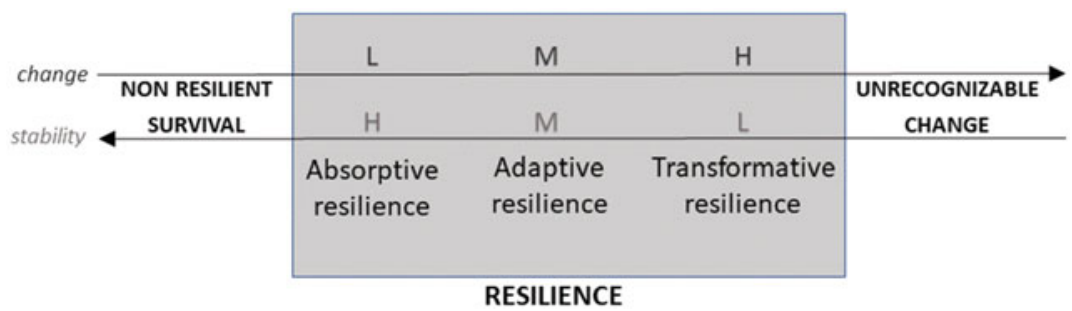

Fig. 1.2 Resilience realm and types (Source Authors' own. Legend: L = Low, $\mathrm{M}=$ Medium, $\mathrm{H}=$ High) 
Transformative resilience shows the ability of the social entity to interact with disturbances and impact on the system's change. In this case, the essence of the social entity is challenged; as the context changes dramatically, there is a high risk that it will be thrown into a completely different reality, where points of reference and consolidated functioning are revolutionized. In the realm of organizations, we could argue that in this case, institutional settings are changing. The social entity must undergo a profound renewal while a continuity with the past can be clearly traced at some level. This renewal acknowledges that the entity has also interacted with the changing context (co-evolution takes place) and that the revolutionary potential of the context is scaled back. In complex systems language (Walker \& Salt, 2006), this type of resilience would keep the entity away from the dramatic and totalizing change entailed by passing the threshold. It is consistent with the definition of resilience as 'adapting within a threshold'; however, it acknowledges that the threshold might change over time and that resilience occurs when the social entity is able to respond to that challenge by remaining within the renewed threshold. Folke et al. (2010) refer to this ability as 'transformability'. At the organizational or system level, transformative resilience occurs in relation to changes in institutional settings (cf. North, 1990) and is measured by the ability to transform together with the setting in order to maintain a position within the threshold-what systems theorists term 'co-evolution' (for a fascinating account of such processes within the context of organizations and markets, see Padgett \& Powell, 2012).

\section{Adversity and Novelty}

While change and stability can be used to typify resilience, they can also be used to characterize its triggers or antecedents, i.e. adversities. Different kinds of adversities require different levels of change and stability and, therefore, resilience. Adversities vary according to their determinateness, being well-known or unknown, expected or unexpected and/or surprising. Giustiniano et al., (2018, p.17) claim that resilience is 'not only a matter of learning but also of 'learning to learn', including the willingness to continuously engage in experimentation and embrace novelty. According to Kayes $(2015$, p. 17), novel experiences are characterized by a lack of apparent task constraints, which means that successful resolution must go beyond typical expertise or established routines. In such situations, neither the goal to be achieved ('what') nor the path to solving 
the problem ('how') are clear, in this way they resemble ill-structured or 'wicked' problems (Rittel \& Weber, 1973). Finally, Kayes (2015, pp. 18-20) points to four types of learning mechanisms: direct experience, counter experience, evidence and trial and error or exploration. Studies have ascertained that different organizations adopt and excel at different types of learning (March, 1991) and that context-specific and locally embedded learning styles emerge over time (Powell, 1998). These styles, in turn, enable organizations to develop distinct preferences or habits when it comes to gathering, processing and acting upon different types of knowledge (Kayes, 2015, p. 21). We follow Frigotto (2020) who proposes that the concept of novelty be used to characterize disturbances and to explain different resilience types in relation to triggers.

Defining resilience in terms of novelty produces three main advantages (Frigotto, 2020). First, it allows us to clarify how resilience can be conceived of as a source of stability by ensuring the maintenance of functionality despite adversity, and as a source of change by stimulating positive adaptation and thriving after adversity. Second, novelty is a relative concept that reflects the state of the art of knowledge (Frigotto, 2018); resilience that refers to novelty is not defined as a fixed set of 'must haves' in relation to a closed set of situations but as a changing ability that is renewed continuously according to new challenges. Third, novelty is also relative in a further sense: since knowledge is not homogenously distributed, novelty does not appear equally to every entity because it maps onto one's own knowledge. As a result of differences in their knowledge, entities will perceive different novelty differently. A definition of resilience grounded in novelty articulates that resilience stimulates learning in various forms (e.g. from others that already know) and at different levels (e.g. new knowledge for some or all).

Building upon the work of Levinthal (2008), novelty can be defined as the opposite of knowledge; novelty consists of what is not known. It can be observed in many forms and at many levels; it has been understood as both an ingredient and as an outcome of change (Frigotto, 2018). Novelty is pervasive, appearing in details or in dramatic changes, and thus can be considered a continuous variable rather than a dichotomous one (Frigotto, 2020).

When we assess the novelty of adversity triggers, we consider three different aspects that reflect novelty dimensions (Frigotto, 2018). First, triggers might be novel, meaning that they are not known and vary according to how distant they are from what is already known; this 
reflects the degree of novelty. For example, when New Public Management (NPM) was recommended as the appropriate approach for public administration (cf. Christensen \& Lxgreid, 2011), it was perceived as having a high novelty degree in relation to public administration theories: it brought principles of management into the public sector that dramatically changed the idea of how public institutions are and should be managed. Conversely, today, the introduction of new efficiency or effectiveness measures represents just an add-on to that framework, which scores lower in novelty degree.

Second, novelty is spatially and temporally relative, so the same instance might appear novel to some observers and not to others, and it might appear differently in different times, for example, in Europe, the way we see lockdowns since the COVID-19 pandemic. Before January 2020 , the idea of a lockdown was largely seen as an unnecessary measure in the contemporary, developed world: it was perceived as something obsolete, concerning the plagues of past centuries, most recently around 1920 , or 'remote' and 'far-away' China. When a lockdown was implemented in Italy in March 2020, it appeared as a major novelty-nobody really knew what lockdown meant or entailed for their everyday behaviour or for the whole economy. Then the lockdown measures slowly spread across Europe, and countries began considering them appropriate and indispensable. A lockdown is no longer a major novelty. When we consider the future (we are writing in June, 2020), a lockdown in the autumn of 2020 seems like a minor or medium novelty. Societies have built up rich knowledge on what the lockdown is and means, and they can also prepare for it in advance. The lesson from this is that novelty should always be assessed in relation to a specific observer at a specific time; otherwise, it is easily misjudged in retrospect. This is what we mean when we refer to novelty's relativity.

Third, novelty awareness refers to whether the lack of knowledge corresponding to novelty is perceived or not-a 'known unknown' or an 'unknown unknown' (Logan, 2009). Building upon the previous example, the World Health Organization, as well as other institutions, warned the world's governments of the risk of pandemics in previous years. This would lead one to think that the COVID-19 pandemic was something which many should have been aware. While the pandemic might have come as a minor surprise to some, to many it was a remote event, either because they downplayed the warnings or because they thought that the progress of the contemporary world would somehow 
shield it from catastrophic effects. Awareness reflects the difficulty of addressing something that we do not know but might exist.

Novelty reflects a condition of the observer that reveals one's need for new knowledge by claiming that something is novel to him/her. Thus, novelty is objectified and transferred to an object. We typically say 'this product is new' or 'this situation is new', indirectly claiming that we had not experienced that product or that situation earlier. This also applies to characterizing adversity triggers according to their novelty profiles. When someone says that an adversity trigger is novel, this means that he/she is not prepared to handle it with his/her current level of knowledge; further, one either does not know that it exists or that its occurrence is likely.

Building upon these considerations, it is possible to advance three novelty profiles (minor, medium and major). Novelty profiles reflect the amount of knowledge that is necessary to make something novel into something known, predictable and expected, contemplated among possible cases, manageable and controllable. Resilience types refer to these profiles (Table 1.3, column 3 ).

Absorptive resilience addresses disturbances that display a low novelty profile: they are temporary and concern a narrow range of well-known external conditions (Holling, 1973, p. 1). When triggers are well defined within given knowledge (low novelty profile), they can easily be understood and typically even specified into a list, and it is possible to routinely prepare against them, thus change can be planned and contained. At the individual level, an example of low novelty profile adversity is stress related to an important project; at the organizational level, a delay in sales for seasonal gifts due to a late season; at the system level, the effects of economic growth in regional and national employment patterns.

Adaptive resilience is associated with a medium novelty profile of adversity triggers, meaning that these are not well known but can either be understood and framed using available knowledge or else they require refinement or moderate knowledge development. In the language of James March's exploitation and exploration trade-off (1991), for adaptive resilience, learning takes place through the exploitation of existing knowledge. At the individual level, an example is a job change; at the organizational level, the need for a new product differentiation; and at the system level, the quest for new regional growth patterns based on smart specialization.

Transformative resilience responds to triggers with a major novelty profile. These are challenging triggers, such as 'sharp shifts,' 'regime 


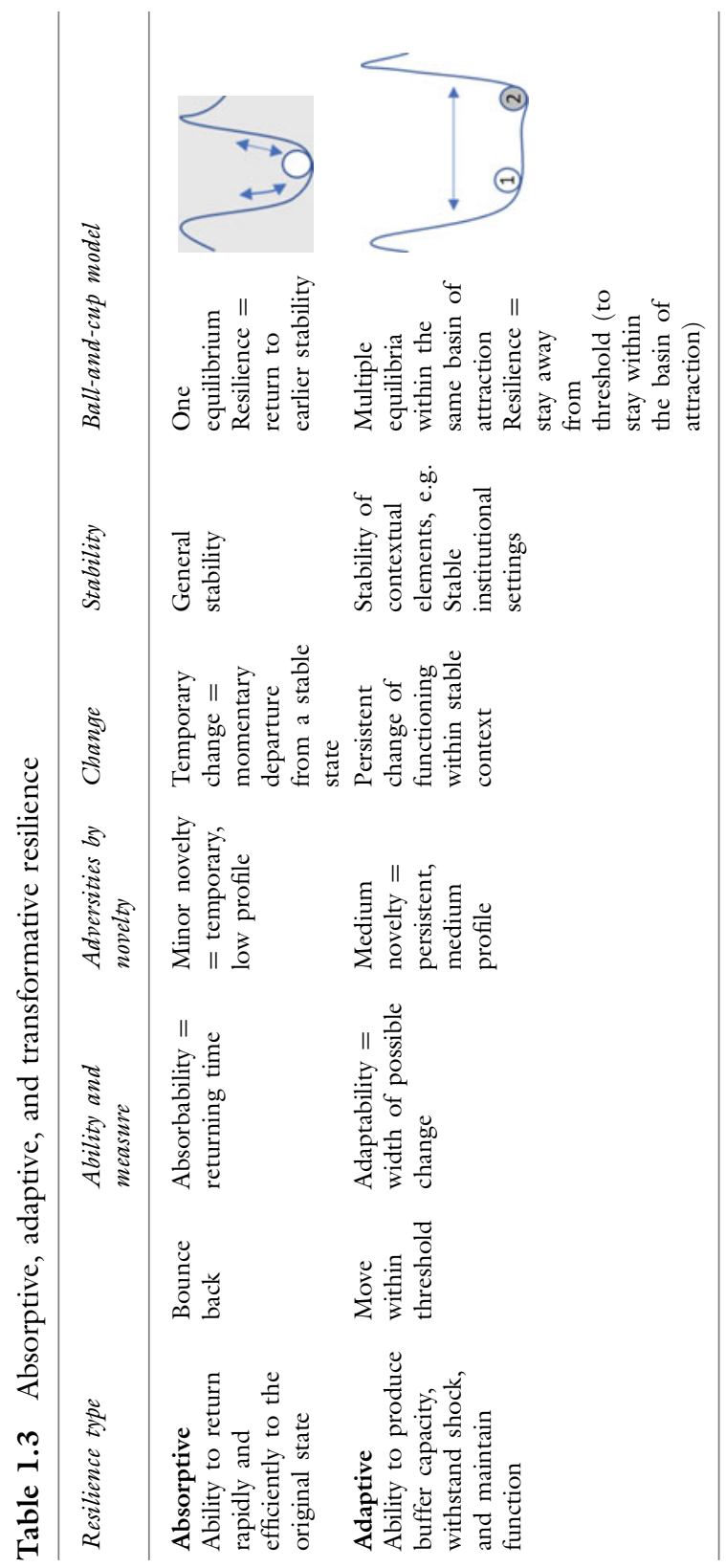


l RESILIENCE IN ORGANIZATIONS AND SOCIETIES ...

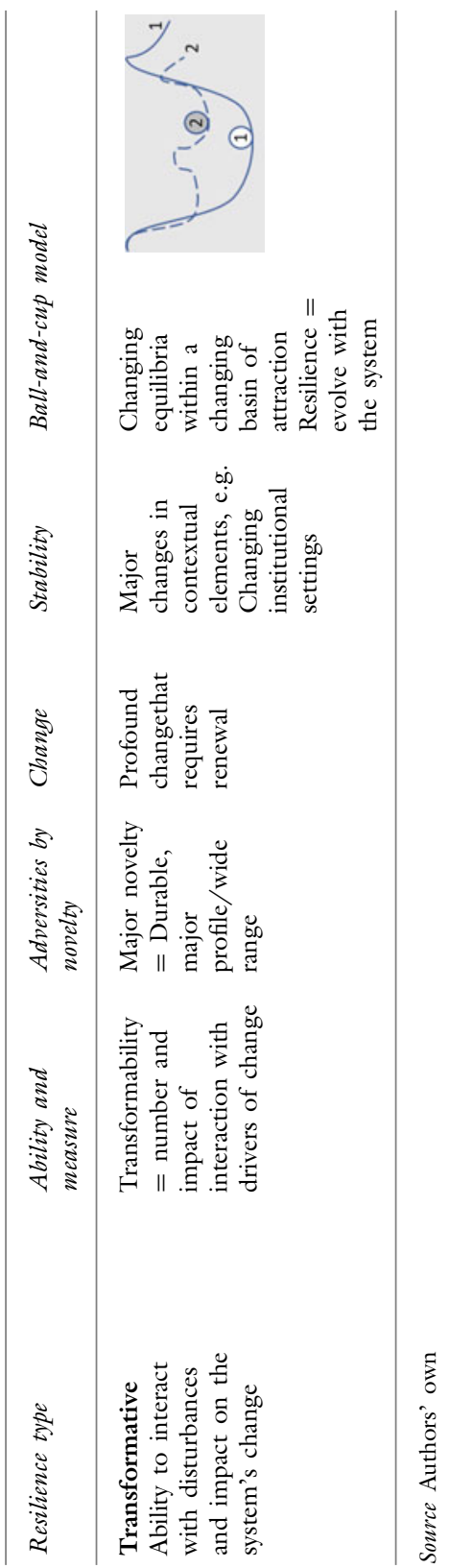


shifts,' or 'critical transitions', and concern a variety of adversities that are typically both unpredictable and unexpected (Folke et al., 2010). Building on March's exploitation and exploration trade-off (1991),transformative resilience entails exploration of new knowledge because learning encompasses all aspects of the social entity and entails the acquisition of solutions that are distant from those building the stable response system. At the individual level, an example is divorce, which can challenge people's internal balance; at the organizational level, a change of customers' preferences; at the system level, Brexit.

\section{Temporality}

Resilience is only demonstrated over time. Thus, in order to define resilience, we need to take temporality into account. As a complex and dynamics process, resilience encompasses different types of nonlinear interactions among sub-elements, both internal and external. What is more, such interactions are laden with contradictory aspects associated with adaptive and proactive prespectives on resilience (Giustiniano et al., 2018 , p. 20), suggesting the importance of approaching the phenomenon from a processual prism. Hence, resilience is perceived not as a state of being, a disposition or a structural property, so much as a processual practice (Feldman \& Orlikowski, 2011) of becoming (Tsoukas \& Chia, 2002)' (Giustiniano et al., 2018, p. 20; emphasis added).

Building upon the works of Frigotto (2020) and Fisher et al. (2019), our perspective encompasses adversity triggers, resilience outcomes, and resilience mechanisms and positions them on a timeline (Fig. 1.3). Considering the chronological deployment of resilience, Fisher et al. (2019) distinguished resilience into mechanisms that take place right after adversity triggers have hit and outcomes that take place after recovering from adversity. The authors also talk about 'resilience promoting factors', which are 'characteristics and features of the self or one's environment that can promote the likelihood of successful adaptation' and also specify that they 'serve as valuable targets for interventions aimed at increasing resilience' (Fisher et al. 2019, p. 25). They acknowledge that these factors impact resilience mechanisms while adversity triggers hits, however, they neglect their own temporal dimension. We acknowledge that these factors also have a temporal deployment and that they are put in place deliberately or simply exist before the resilience mechanisms are activated. This form of resilience pertains to 'the potential for adjusting patterns 


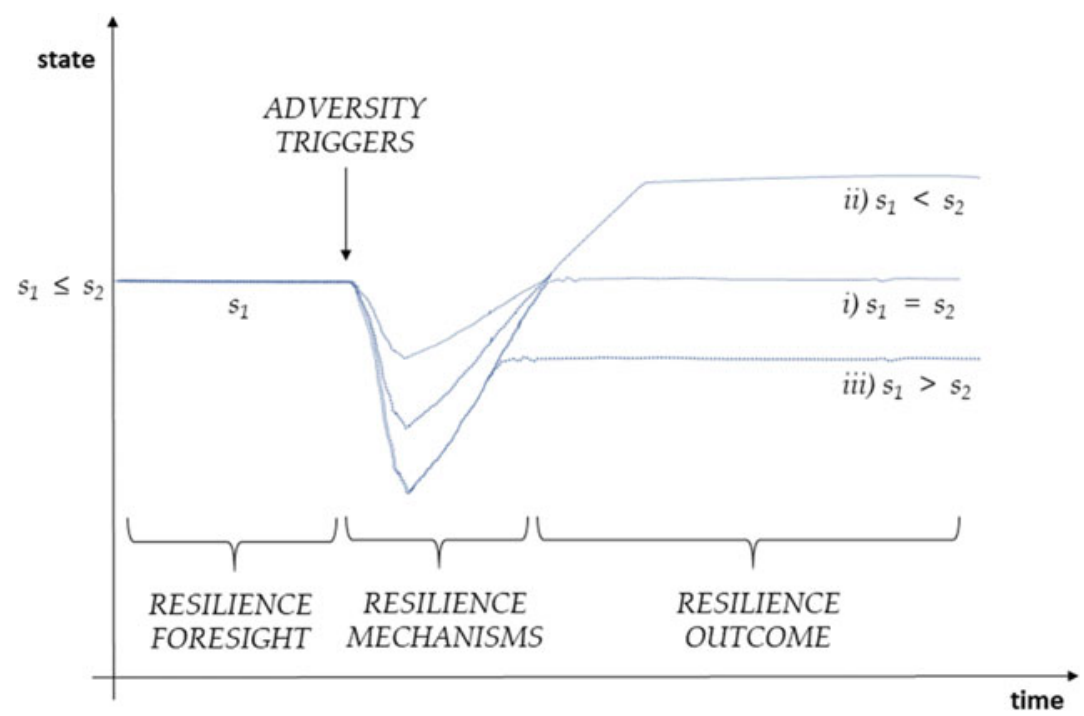

Fig. 1.3 Resilience temporal dimension (Source Authors' own, following Fisher et al., 2019; Frigotto, 2020)

of activities to handle future changes in the kinds of events, opportunities and disruptions experienced'; therefore, it exists before disturbances call upon them (Woods, 2019, p. 53). We term the actions that take place before the occurrence of triggers, and that support resilience mechanisms, resilience foresight. Thus, our definition of resilience is temporally defined as follows (Fig. 1.3): resilience foresight (before); resilience mechanisms (during) and resilience outcomes (after).

Regarding the 'final state' $\left(\mathrm{s}_{2}\right)$ at which resilience outcome stabilizes, there are two main perspectives in the literature (Duchek, 2020). The first states that an entity is resilient if it returns to the initial state; here, the emphasis is on resuming standard performance (Lengnick-Hall et al., 2011). The second understands the resilient entity as one that has coped, thrived and reached another state; this has been interpreted by some as entailing higher performance levels (Burnard \& Bhamra, 2011; Hamel \& Välikangas, 2003). A further position allows the resilient entity to 'bounce forward', i.e. grow or become stronger for future challenges (Giovannini et al., 2020; Vogus \& Sutcliffe, 2007). Some authors subordinate resilience to a stable or increased performance despite adversity. Others 
associate resilience with a more neutral idea of evolution or a broader conception of development at some level. For instance, for Vogus and Sutcliffe $(2007$, p. 3418$)$ the concept of organizational resilience entails 'the maintenance of positive adjustment under challenging conditions such that the organization emerges from those conditions strengthened and more resourceful'. Moreover, resilience enhances and emphasizes the ability of systems to resist despite adversity, and, in other words, might seem to suggest survival. Nevertheless, mere survival does not entail resilience. In our perspective, resilience can be associated with any of these three main situations if the system is characterized by both stability and change (Fig. 1.2): (i) the initial and final states, after adversity triggers have hit, are the same; (ii) the final state is better than the initial state; (iii) the final state is worse than the initial state (Fig. 1.3). While resilience has a positive connotation, it is to be interpreted in terms of the maintenance of essence combined with change rather than an assessment of the state based on other criteria-e.g. job satisfaction (individual level), business leadership (organizational level), or economic or social welfare (system level).

Absorptive resilience responds to disturbances with a low novelty profile that can be easily anticipated, making resilience foresight processes consist of risk assessments and contingency plans. Mechanisms enacted in response to adversity could therefore be learned in advance so that during the period of adversity, the depth of the nadir is smaller, recovery is quicker, and the resilience outcome includes the little changes that derive from experiencing and practicing what is known in theory.

Adaptive resilience concerns a medium novelty profile of adversity that can be addressed by leveraging the relativity dimension (looking at available knowledge from others) or by targeting the 'known unknowns'. Resilience mechanisms are somewhat limited in terms of finding, implementing, or including novelty, but the nadir is typically small. The resilience outcome reflects important changes the social entity has implemented while responding to adversities and that persist also in the ex-post phase. These changes might set $s_{2}$ at different levels even though it is reasonable to think that it would typically not be the case of $s_{1}=s_{2}$.

Transformative resilience is associated with triggers with a major novelty profile that can be tackled in foresight only through a substantial effort to address the 'unknown unknowns'. Mechanisms that respond to adversities might be very hard to find and implement, so the nadir might be very deep. The resilience outcome might vary substantially but 
encompasses significant changes that can end into very different outlooks of the social entity being considered.

\section{Scales of Resilience}

While clear in principle, when analysing social entities, it is not straightforward to grasp when change and stability are both present or under which circumstances change leads to the abandonment of a previous essence; so that either a red thread between the past and present cannot be detected, or in which change has not occurred at all and the persistence of the entity is simply accidental. ${ }^{3}$

Taking an example from the organizational realm, many corporations go bankrupt as a result of technological and market disruptions, with only a handful being able to survive more than half a century (Peters et al., 1982). In contrast, a handful of businesses have been able to successfully adapt by moving into new markets and by adopting different ways of organizing. Nokia has become a landmark case of resilience. In the 1860s, Nokia was a pulp and paper company. It gradually moved into the rubber and cable businesses, followed by electronics (TV and ICT) and network and mobile technologies in the 1990s and lately the consumer market (Borhanuddin \& Iqbal, 2016). Kurikka et al. (2018) present Nokia as a case of regional resilience while Nair et al. (2014) as a case where resilience was missing. Nokia experienced tremendous change throughout its existence, and whether it still preserves a continuity of essence can be debated. Moreover, the outcome of this evaluation might be different depending upon who is assessing it (company members-top management/employees, shareholders, stakeholders, Finnish/global society) and on what level (business competition, innovativeness, societal role). For instance, one could argue that, while it has changed in terms of business, Nokia has remained an important contributor to Finland's GDP and labour market. The Nokia case illustrates the difficulty of setting absolute, clear-cut parameters for assessing the resilience of real organizations, individuals and social systems.

3 As Walker et al. (2014, p. 3) stated, 'Because of the possibility of multiple stable states, when considering the extent to which a system can be changed, return time doesn't measure all of the ways in which a system may fail-permanently or temporarily-to retain essential functions.' See also Folke et al. (2010, p. 4). 
Carpenter et al. (2001) contend that resilience changes depending on the temporal, spatial and social scale at which the measurement is made. On the temporal scale, in prehistory, the adoption of iron axes facilitated the emergence of the agricultural economy, as forests could be cut more easily and quickly to create fields. In this sense, the use of iron axes supported resilience at one time. Nevertheless, it also resulted in soil infertility, which demonstrates that resilience at one time may come at the expense of resilience at another (Carpenter et al., 2001, p. 767).

On the spatial scale, resilience can at once take place in one place and not in another. During the COVID-19 pandemic, this point was largely debated when the effectiveness of different national strategies was discussed. Consider two countries with potentially similar contagion incidence: as of the time of writing (summer 2020)—Sweden and Norway. Sweden displayed one of the world's highest mortality levels (4874 deaths) while the nearby Norway recorded 242 deaths (Lindeberg, 2020).

Finally, on the social scale, it is argued that resilience can be analysed at three main levels-i.e. individual (micro), organization (meso) and system (macro)-and that resilient entities (e.g. organizations and societies) can translate or incorporate resilience from one level to the other (Kayes, 2015, p. 16). Giovannini et al. (2020, p. 7) claim that a resilient society is one in which individuals are resilient, and public intervention should enhance and complement people; although societal resilience is not the sum of individual resilience as social ties, community-level capacities and institutions play a role. Conversely, Carpenter and colleagues (2001) stress that these levels do not entail consistency with one another, as smaller systems are nested in larger systems, and as a result, they coevolve and interact in nonlinear and unpredictable ways (Walker et al., 2004), showing that the micro-macro relationship of levels in resilience is complex.

The cases presented in this edited volume lend credence to these scales and demonstrate empirically that it is always necessary to specify which time, space and level of analysis is being referred to when discussing resilience.

\section{Rationale AND Scope of The Volume}

This edited volume brings together scholars in the fields of human research management, public policy, regional studies and organization 
theory around the concept of resilience. This is done in an effort to provide a more holistic understanding of this complex phenomenon from a multi-sectorial, cross-national and multidisciplinary perspective. Each chapter brings to the book a contribution on resilience that is built in relation to their area of research and to specific key references on resilience largely adopted in that area. Overall, the volume builds a conversation across the diverse specializations and attentions provided by each chapter. Also, and more broadly, the authors contribute both to theory testing and development and provide key empirical insights useful for societies, organizations and individuals that are experiencing disruptive pressures. Diverse chapters are held together by a clear organization of the volume across levels of analysis (resilience in organizations and the organizational fields and societies in which individuals and organizations are embedded in) and by an original perspective on resilience that we derive from our review of the literature and existing knowledge gaps, according to which we position and connect each of the individual chapter contributions.

In this book, resilience is investigated in cases that display a substantial level of publicness. This pertains to the concept introduced by Barry Bozeman. Bozeman and colleagues have long advocated for a move away from the traditional binary distinction public vs. private (e.g. Christensen et al., 2007; Farnham \& Horton, 1999) towards the notion that all organizations are in essence public, given that they are all affected by the technical and institutional environments in which they operate (Bozeman, 1984, 2004; Bozeman \& Bretschneider, 1994). In short, for Bozeman the key is not whether organizations are public or private, but to what extent their goals, structures and activities are determined by political and economic authority in the form of state regulations and other forms of coercive behaviour. 'Publicness is not viewed as an absolute quality but as a dimension. The dimension is defined by the organization's mix of economic and political authority as a basis of its activity' (Bozeman, 2004, p. 78). The degree of publicness is then defined by the extent to which externally imposed political authority affects organizational activities-goals, mission, funding, strategy, management, etc.

The cases presented in the individual chapters, which span across the public and private sectors, vary in terms of publicness. Yet, because this dimension makes our cases 'revelatory' for the holistic study of resilience (Yin, 2009 [1984]), they 'offer high potential for developing new insight into an understudied phenomenon' (Langley \& Abdallah, 2011 , p. 118). That said, the majority of the chapters focus on cases that 
are consistently subject to environmental adversities and disturbances, as they are, by definition, subject to external and highly political drivers. Thus, because of their inherent publicness, not only do these contexts allows us to focus on the effects of external dynamics in resilience, but also enable us to compare cases that cut across a multiplicity of sectors and national contexts. In a nutshell, our argument is that publicness stimulates resilience most, because it entails a higher level of exposure to external requirements for change. Yet, as a downside, it also entails a higher risk of paralysis or inertia if and when resilience is not cultivated.

\section{Presentation of the Chapters}

The heart and empirical foundation of the edited volume is structured into two main sections with five chapters each; the first concerns resilience in organizations, and the second concerns within organizational fields and resilience in societies. The case chapters present a variety of adversity triggers that illustrate different novelty profiles (Table 1.4).

In the first section, Chapter 2 addresses the organizational ability to conduct problem solving and learning in the midst of a crisis by exploring the case of a fire brigade's reaction to a novel and unexpected cause of a fire. We see how organizations can face unknown problems that are mistakenly taken as known. Not recognizing the novelty of the problem can lead to failure, as the organization follows rules and norms that are not appropriately adapted to the situation. Hence the ability to rapidly detect novelty and be able to insert new findings quickly and effectively into the problem representation throughout the organization is essential to building resilience. While there are lessons in this case that can help organizations to cultivate resilience, the chapter focuses on resilience in the midst of a crisis. It addresses resilience mechanisms that can be adopted to address major novelty and elaborates on structures and practices that can be developed in advance to support resilience mechanisms.

Chapter 3 brings us to a military context, in which traditional rulefollowing is the expectation; however, we see that the Austrian military seeks to instil in its soldiers the ability to deal with surprising situations. Drills and rule-following have limits even in highly structured organizations like the Austrian military. Resilience requires the ability to understand when to break rules, and paradoxically, the military has 


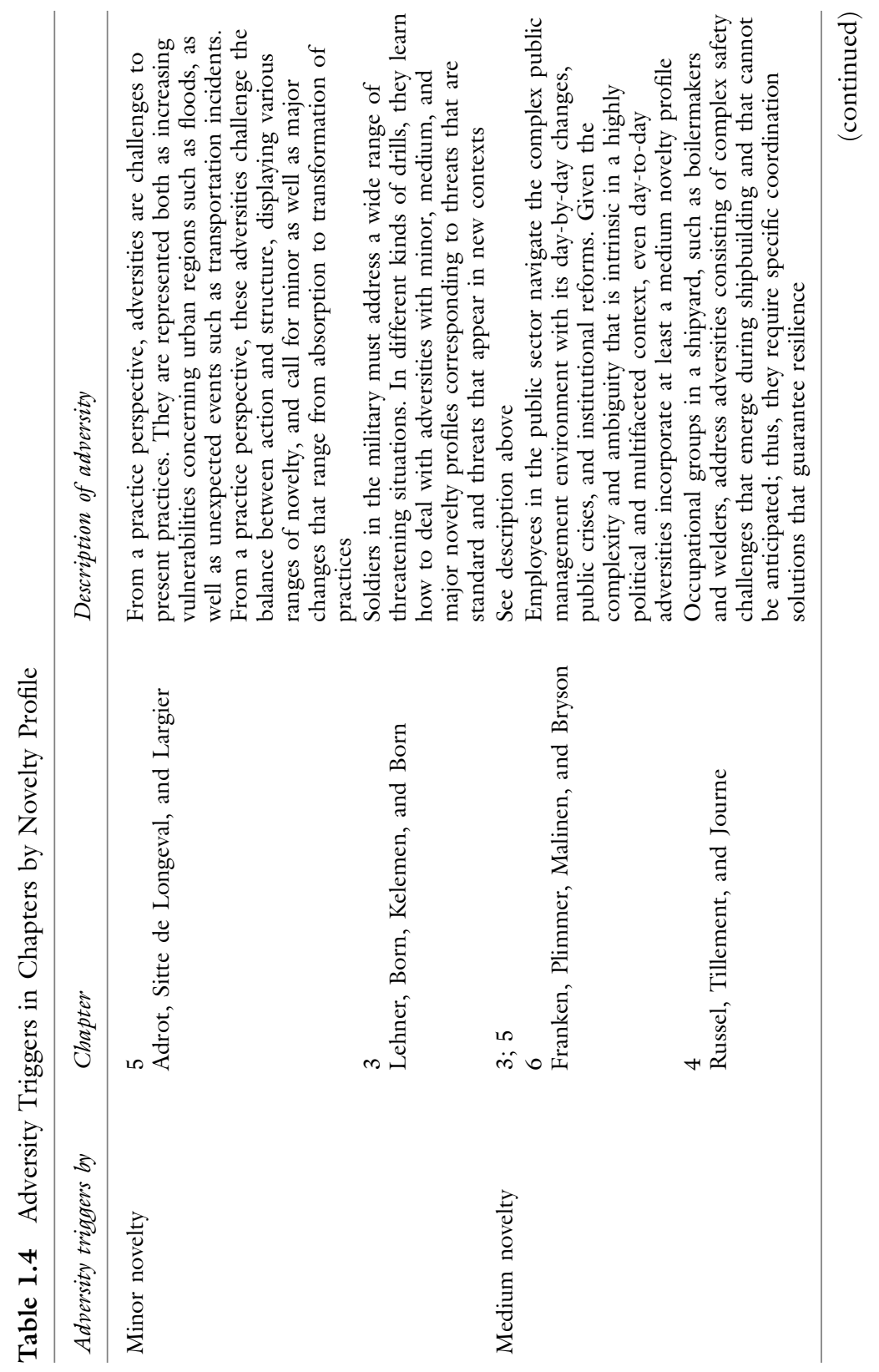




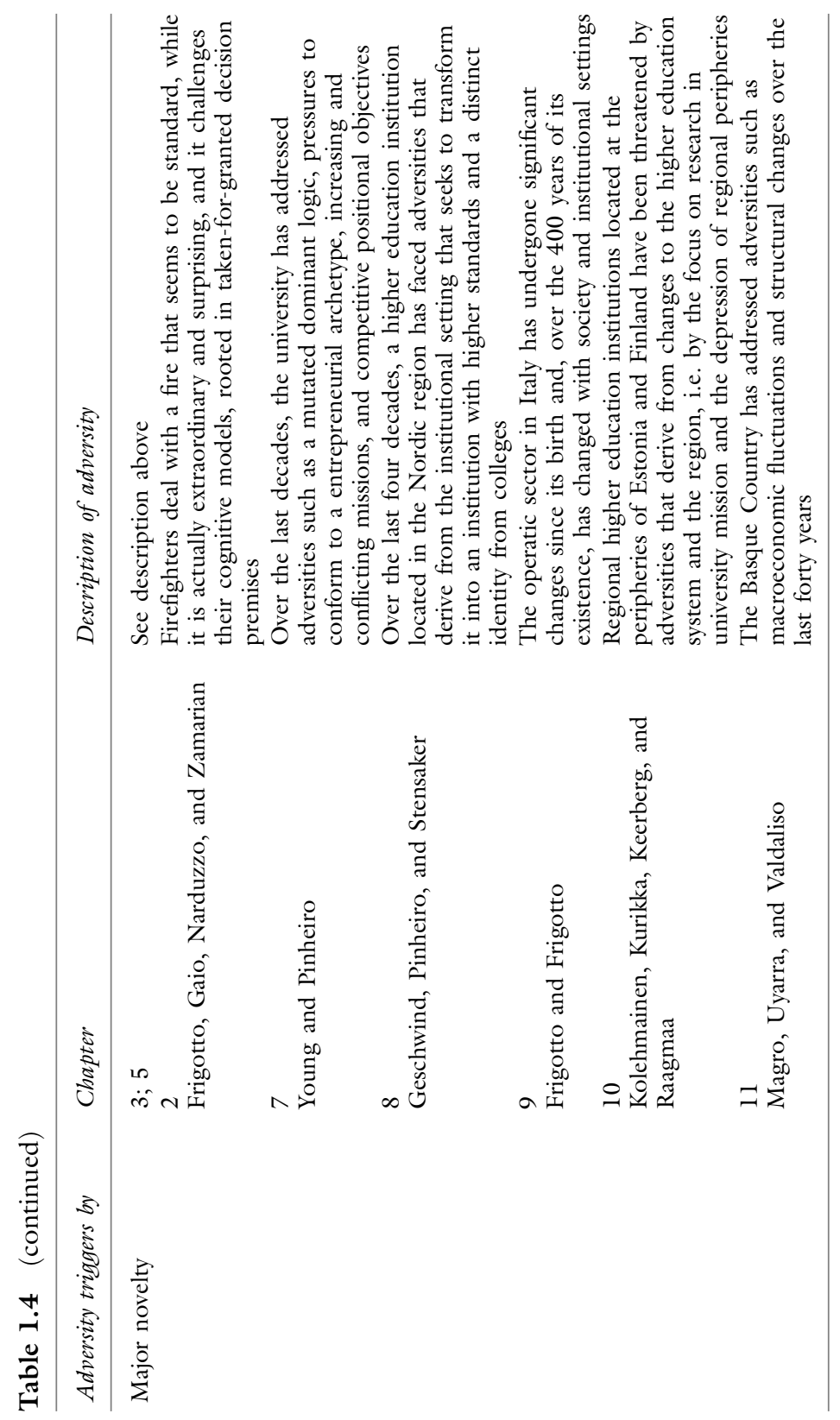


developed a unique form of drill (preadaptive drill) to allow for decisionmaking in complex situations and to develop resilience foresight. During drills, soldiers learn mechanisms that can be acquired in advance in relation to different novelty profiles of adversities. Drawing on the biological resilience literature, the authors use the concept of 'exaptation'-using old means to achieve new ends (Gould \& Verba, 1982) - to explain how this works.

Chapter 4 traces boilermakers in a naval shipbuilding project. The context of temporary organizing under which the boilermakers operate allows the authors to address resilience in situations in which there is not a 'shared culture' of routines and habits, which is what Chapters 2, 5 and 6 presuppose. Concerning mainly resilience mechanisms, Chapter 4 presents how occupational groups working together for the construction of complex products, i.e. ships, build resilience by setting up special coordination mechanisms. The latter bring together the different groups around one priority that is, avoiding coactivity constraints that are related to unexpected events and challenge workers' safety. Adversity, in this chapter, is understood as coming from complex tasks that are undertaken by independent actors, which inevitably do not go exactly according to plan, but which could result in calamitous accidents or a non-functional ship if not addressed. In other words, there is an invisible threat. Treating it this way emphasizes how resilience can be built ex-ante.

Chapter 5 looks closely at two public agencies-one dealing with coordination for resilience and the second with public transportation. There is a deliberate attempt to build resilience into these two types of public agency. The authors treat resilience as a practice rather than as a behaviour to emphasize the dynamic interplay between structure and action. Particularly important here is the idea of 'teleo-affective structures', which introduce emotive elements and extend behavioural drivers beyond rules and norms. The chapter distinguishes between cultivating resilience for predictable situations - in which adversity can be anticipated-and those that are the result of a complex environment, in which it cannot. Here again we see the theme of control as a threat, this time expressed not as acting according to norms or micromanagement, but as following prescribed actions. The chapter focuses on resilience foresight and presents organizational arrangements adopted by public organizations to produce resilience before adversity triggers actually occur. The authors show that foresight was triggered in different ways in the two organizations that they studied: one created dedicated crisis management 
teams to develop the capabilities needed to be resilient, and the other redefined organigrams and engaged in task distribution.

Chapter 6 looks at public managers in New Zealand in a general public sphere context. The authors focus on deliberate attempts to build resilience. Adversity in this case comes as the result of an ambiguous and complex context, one in which an overexertion of control, through micromanagement, can lead to failure. Unlike in Chapter 2, there is no surprise to uncover and 'know' but rather a situation of task complexity in which uncertainty continues to prevail over time. The authors treat resilience as a capability that can be learned and harnessed through leadership. The chapter addresses resilience in foresight: employees prepare their resources to be ready to adapt and flourish at work and when faced with challenging circumstances.

The second section of the volume includes cases that position resilience on a macro level within organizational fields and in society. Chapters in this section are clustered into those that address intra-system resilience and those addressing inter-system resilience. Chapters 7,8 and 9 belong to the first set, as they analyse one system intended as a whole sector. Chapter 10 analyses several systems that coevolve with each other in a region, and Chapter 11 concerns the whole economic dynamics of the region.

Chapter 7 contributes to the literature on resilience foresight, as it discusses the evolution of universities as institutions, and to mechanisms, as it identifies the archetype of the post-entrepreneurial university as more consistent with threats deriving from general institutional change. In this chapter, the authors demonstrate how the concept of an entrepreneurial university, and the political and economic pressures driving it to become a global archetype, embeds logics that if pursued are likely to undermine the resilience of universities. Drawing on complex systems theory, the chapter looks at how the broad aims of efficiency, diversity and unified actorness are misconstrued in the entrepreneurial university literature and suggests ways to reconfigure universities to be resilient by orienting them to loose coupling, slack and requisite diversity.

Chapter 8 examines the linkage between identity and resilience at a Scandinavian university. By looking at a series of critical junctures in which external adversity coming from the government and the private sector threatened to undermine the university's identity, it explores the possibility of understanding resilience through a dynamic process organization identity formation and evolution that brings together both the 
internal cultural and teleo-affective structures discussed in Chapter 5 with externally determined possibilities for legitimacy. Addressing both mechanisms and outcomes, it elaborates on the role of organizational identity in resilience, as identities constrain and enable social agents' attempts to respond to environmental imperatives and to enact the resilient behaviour.

Chapter 9 provides a historical analysis of the evolution of the opera organizational field in Italy, and fosters a discussion on the actual resilience of the sector in relation to the prominent changes that transformed both the society and the opera over time. It discusses the outcomes of the resilience of the operatic sector throughout its history. While challenged by deep societal, cultural and economic changes, the opera went through a transformative resilience that required scaling down its importance as a cultural expression, and this translated into the reduction of the number of opera houses and of their funding. The authors conclude that the operatic sector is still wandering between different target publics that can support its existence-ranging from tourists to citizens, from intellectuals to lay people, from young people to adultsand that for this reason, its resilience, as the ability to combine change with essence, is continuously threatened by the option of becoming the Disneyland of the opera, focusing on mere reproduction and businessdrawn entertainment.

Chapter 10 examines regional higher education institutions (RHEIs) in peripheral regions of both Finland and Estonia. While most of the literature on resilience focuses on a single type of entity or system, this chapter addresses universities as nested subjects of two different societal systems, higher education and the region, which each create a distinct form of adversity. Resilience comprises the co-evolution of RHEIs with the region in which they are positioned, as well as with the higher education system in which they operate. It is analysed in terms of mechanisms concerning the governance that regulates interactions among institutions, such as resource allocation decisions and core competencies.

Chapter 11, via a historical analysis, presents how a vibrant and culturally-disctinctive economic region the Basque region, was able to navigate through economic and institutional changes. This case shows the link between resilience and governance systems, especially industrial and innovation policies. Building on the field of evolutionary economic geography, it explores both the unexpected and predictable threats to regions that can come from recessions, crises and structural changes to the broader national and global economy. The authors distinguish between 
situations in which regions maintain previous economic specialization and those in which they shift towards new paths; they call them 'adaptation' and 'adaptability' — citing Boschma (2015)—-two forms of resilience that refer to the three abilities of the conceptual typology presented above: absorbability, adaptability and transformability.

\section{FINAL REMARKS}

In this edited book, the chapters present cases that display a high degree of publicness (Bozeman, 2004), a dimension that pushes social entities to cultivate resilience.

The chapters are grounded in different disciplinary perspectives or research streams that address organizations and societies. The result is a multidisciplinary perspective on resilience that enhances best practices and cross-fertilization of findings, theories and methods throughout the social sciences.

According to Collin (2009, p. 103), multidisciplinarity refers to cases in which different disciplines work independently on different aspects of a project and within their boundaries. In contrast, interdisciplinarity refers to the reciprocal recognition of contributions and perspectives within different disciplines, while transdisciplinarity refers to the integration of such perspectives into a harmonized, coherent whole.

Our aim is to trigger future interdisciplinary and/or transdisciplinary research that produces a holistic understanding of resilience and to support policymakers, managers, regional/local planners and scholarly communities in pursuing resilience as important for our present and future organizations and societies. These imperatives have become ever more urgent as individuals, organizations and societies deal with the challenges posed by the COVID-19 pandemic alongside the grand challenges facing humankind, with climate change at the forefront.

We presented our perspective on resilience along two key phases. First, we reviewed the literature on resilience and identified change and stability, as well as the temporal dimension, as its most fundamental traits. Then, we elaborated the absorptive, adaptive and transformative resilience typology and the temporal sequence of foresight, mechanisms and outcomes. This novel theoretical and analytical framework allows us to map resilience consistently onto a variety of cases and to maintain a general 'umbrella-concept' that unifies them. 
Second, our organizing principles act as a 'lens' through which the individual chapters can be interpreted and compared to generate a holistic perspective on resilience while respecting the specific conceptual and theoretical perspectives and postulates being followed by the individual authors in their respective contexts.

The final chapter of this edited volume reassesses and discusses the core conceptual and theoretical premises sketched out in this introductory chapter against the backdrop of the empirical contributions of the individual, case chapters and the volume as a whole. In so doing, we hope to provide a valuable platform for future studies and policy debates on this critically important societal phenomenon.

\section{REFERENCES}

Bazerman, M., \& Watkins, M. (2004). Predictable surprises: The disasters you should have seen coming, and how to prevent them. Harvard Business School Press.

Bhamra, R. (2016). Organisational resilience: Concepts, integration, and practice. CRC Press.

Bhamra, R., Dani, S., \& Burnard, K. (2011). Resilience: The concept, a literature review and future directions. International Journal of Production Research, $49(18), 5375-5539$.

Bodin, P., \& Wiman, B. (2004). Resilience and other stability concepts in ecology: Notes on their origin, validity, and usefulness. ESS Bulletin, 2(2), 33-43.

Borhanuddin, B., \& Iqbal, A. (2016). Nokia: An historical case study. Electronic Journal of Computer Science and Information Technology: Ejcist, 6(1), 1-14.

Boschma, R. (2015). Towards an evolutionary perspective on regional resilience. Regional Studies, 49(5), 733-751.

Bozeman, B. (1984). Dimensions of publicness: An approach to public organization theory. In Bozeman, B., Straussman, J. (Eds.), New directions in public administration (pp. 46-62). Belmont, CA: Crooks/Cole.

Bozeman, B. (2004). All organizations are public: Comparing public and private organizations. Beard Books.

Bozeman, B., \& Bretschneider, S. (1994). The 'publicness puzzle' in organization theory: A test of alternative explanations of differences between public and private organizations. Journal of Public Administration Research and Theory, 4(2), 197-224.

Britt, T., Shen, W., Sinclair, R., Grossman, M., \& Klieger, D. (2016). How much do We really know about employee resilience? Industrial and Organizational Psychology, 9(2), 378-404. 
Bruneau, M., Chang, S. E., Eguchi, R. T., Lee, G. C., O’Rourke, T. D., Reinhorn, A. M., Shinozuka, M., Tierney, K., Wallace, W. A., \& von Winterfeldt, D. (2003). A framework to quantitatively assess and enhance the seismic resilience of communities. Earthquake Spectra, 19(4), 733-752.

Burnard, K., \& Bhamra, R. (2011). Organisational resilience: Development of a conceptual framework for organisational responses. International Journal of Production Research, 49(18), 5581-5599.

Carpenter, S., Walker, B., Anderies, J., \& Abel, N. (2001). From metaphor to measurement: Resilience of what to what? Ecosystems, 4, 765-781.

Christensen, T., \& Lxgreid, P. (2011). The Ashgate research companion to new public management. Ashgate.

Christensen, T., Lægreid, P., Roness, P. G., \& Røvik, K. A. (2007). Organization theory and the public sector: Instrument. Taylor \& Francis.

Collin, A. (2009). Multidisciplinary, interdisciplinary, and transdisciplinary collaboration: Implications for vocational psychology. International Journal for Educational and Vocational Guidance, 9(2), 101-110.

Coutu, D. L. (2002). How resilience works. Harvard Business Review, 80(5), 46-56.

de Bruijne, M. L. C., Boin, A., \& van Eeten, M. J. G. (2010). Resilience. Exploring the concept and its meaning. In L. K. Comfort, A. Boin, \& C. C. Demchak (Eds.), Designing resilience. Preparing for extreme events (pp. 13-32). Pittsburg: University of Pittsburg Press.

Donaldson, L. (2001). The contingency theory of organizations. Sage Publications.

Duchek, S. (2020). Organizational resilience: A capability-based conceptualization. Business Research, 13, 215-246.

Farnham, D., \& Horton, S. (1999). Managing public and private organisations. In S. Horton \& D. Farnham (Eds.), Public management in Britain (pp. 2645). Palgrave.

Feldman, M. S., \& Orlikowski, W. J. (2011). Theorizing practice and practicing theory. Organization Science, 22(5), 1240-1253.

Fisher, D. M., Ragsdale, J. M., \& Fisher, E. C. (2019). The importance of definitional and temporal issues in the study of resilience. Applied Psychology, $68,583-620$.

Folke, C., Carpenter, S. R., Walker, B., Scheffer, M., Chapin, T., \& Rockström, J. (2010). Resilience thinking: integrating resilience, adaptability and transformability. Ecology and Society, 15(4), 20.

Frigotto, M. L. (2018). Understanding novelty in organizations: A research path across agency and consequences. Chem: Springer International Publishing.

Frigotto, M. L. (2020). Reframing resilience on novelty and change. In E. Powley, B. Caza, \& A. Caza (Eds.), Research handbook on organizational resilience (pp. 53-69). Emerald Group Publishing Limited. 
Gilboa, I., \& Schmeidler, D. (1995). Case-based decision theory. The Quarterly Journal of Economics, 110, 605-639.

Giovannini, E., Benczur, P., Campolongo, F., Cariboni, J., \& Manca, A. (2020). Time for transformative resilience: The COVID-19 emergency (EUR 30179 EN). Publications Office of the European Union. ISBN 978-92-76-18113-2 (online first).

Giustiniano, L., Clegg, S. R., Cunha, M. P., \& Rego, A. (2018). Elgar introduction to theories of organizational resilience. Edward Elgar Publishing.

Gotham, K. F., \& Campanella, R. (2010). Toward a research agenda on transformative resilience: Challenges and opportunities for post-trauma urban ecosystems. Critical Planning, 17(Summer), 9-23.

Gould, S. J., \& Verba, E. S. (1982). Exaptation-a missing term in the science of form. Paleobiology, 8, 4-15.

Grove, K. (2018). Resilience. Routledge.

Hamel, G., \& Välikangas, L. (2003). The quest for resilience. Harvard Business Review, 81(9), 52 .

Head, B. W. (2008). Wicked problems in public policy. Public Policy, 3(2), 101118.

Holling, C. S. (1973). Resilience and stability of ecological systems. Annual Review of Ecology and Systematics, 4(1), 1-23.

$\mathrm{Hu}, \mathrm{X}$., \& Hassink, R. (2017). Exploring adaptation and adaptability in uneven economic resilience: A tale of two Chinese mining regions. Cambridge Journal of Regions, Economy and Society, 10(3), 527-541.

Kalpakjian, S., \& Schmid, S. R. (2016). Manufacturing processes for engineering materials. Boston: Pearson.

Kayes, D. C. (2015). Organizational resilience: How learning sustains organizations in crisis, disaster, and breakdown. Oxford University Press.

Knight, F. H. (1921). Risk, uncertainty, and profit. Houghton Mifflin.

Kossek, E. E., \& Perrigino, M. B. (2016). Resilience: A review using a grounded integrated occupational approach. The Academy of Management Annals, 10(1), 729-797.

Kurikka, H., Kolehmainen, J., \& Sotarauta, M. (2018). Constructing regional resilience in a knowledge economy crisis: The case of the Nokia-led ICT industry in Tampere. In P. Benneworth (Ed.) Universities and regional economic development (pp. 163-179). Routledge.

Langley, A., \& Abdallah, C. (2011). Templates and turns in qualitative studies of strategy and management. In D. D. Bergh \& D. J. Ketchen (Eds.), Building methodological bridges (Research Methodology in Strategy and Management, Vol. 6, pp. 201-235). Emerald Group Publishing Limited.

Lengnick-Hall, C., Beck, T., \& Lengnick-Hall, M. (2011). Developing a capacity for organizational resilience through strategic human resource management. Human Resource Management Review, 21(3), 243-255. 
Levinthal, D. A. (2008). Explorations in the role of novelty in organizational adaptation: An introductory essay. In J. G. March (Ed.), Explorations in organizations (pp. 95-103). Stanford Business Books.

Lindeberg, R. (2020, June 15). Sweden's Prime Minister rejects criticism of coronavirus strategy. Time. https://time.com/5853595/sweden-coronavirus-loc kdown-criticism/.

Linnenluecke, M. K. (2017). Resilience in business and management research: A review of influential publications and a research agenda. International Journal of Management Reviews, 19(1), 4-30.

Logan, D. C. (2009). Known knowns, known unknowns, unknown unknowns and the propagation of scientific enquiry. Journal of Experimental Botany, $60(3), 712-714$.

Manca, B., Benczur, P., \& Giovannini, E. (2017). Building a scientific narrative towards a more resilient EU society, Part 1: A conceptual framework. JRC Science for Policy Report. European Commission.

Manyena, S. B. (2006). The concept of resilience revisited. Disasters, 30(4), 434450 .

March, J. G. (1991). Exploration and exploitation in organizational learning. Organization Science, 2(1), 71-87.

McDonald, N. (2006). Organisational resilience and industrial risk. In Hollnagel, E., DD Woods, N. Leveson (Eds.), Resilience engineering: Concepts and precepts (pp. 155-179). Hampshire: Ashgate.

Meadows, D. H., Meadows, D. L., Randers, J., \& Behrens, W. W. (1972). The limits to growth. New York, pp. 27, 102.

Nair, H. A., Sri Ramalu, S., \& Kumar, M. (2014). Impact of innovation capacity and anticipatory competence on organizational health: A resource based study of Nokia, Motorola and Blackberry. International Journal of Economic Research, 11(2), 395-415.

North, D. C. (1990). Institutions, institutional change, and economic performance. Cambridge University Press.

Padgett, J. F., \& Powell, W. W. (2012). The emergence of organizations and markets. Princeton University Press.

Peters, T. J., Waterman, R. H., \& Jones, I. (1982). In search of excellence: Lessons from America's best-run companies. Harper Collins.

Pike, A., Dawley, S., \& Tomaney, J. (2010). Resilience, adaptation and adaptability. Cambridge Journal of Regions, Economy and Society, 3(1), 59-70.

Pirotti, G., \& Venzin, M. (2016). Resilient organizations: Responsible leadership in times of uncertainty. Cambridge University Press.

Powell, W. W. (1998). Learning from collaboration: Knowledge and networks in the biotechnology and pharmaceutical industries. California Management Review, 40(3), 228-240. 
Ramanujam, R., \& Roberts, K. H. (Eds.). (2018). Organizing for reliability: A guide for research and practice. Stanford University Press.

Rittel, H. W., \& Webber, M. M. (1973). Dilemmas in a general theory of planning. Policy Sciences, 4(2), 155-169.

Roe, E., \& Schulman, P. R. (2008). High reliability management: Operating on the edge (Vol. 19). Stanford University Press.

Ruiz-Martin, C., López-Paredes, A., \& Wainer, G. (2018). What we know and do not know about organizational resilience. International Journal of Production Management and Engineering, 6(1), 11-28.

Ruth, M., \& Goessling-Reisemann, S. (2019). Handbook on resilience of sociotechnical systems. Cheltenham, UK \& Northampton, MA: Edward Elgar Publishing.

Satyal, P., Shrestha, K., Ojha, H., Vira, B., \& Adhikari, J. (2017). A new Himalayan crisis? Exploring transformative resilience pathways. Environmental Development, 23, 47-56.

Schaffer, A., \& Schneider, M. (2019). Towards a responsible resilience. In M. Ruth \& S. Goessling-Reisemann (Eds.), Handbook on resilience of sociotechnical systems (pp. 9-29). Edward Elgar Publishing.

Tsoukas, H., \& Chia, R. (2002). An organizational becoming: Rethinking organizational change. Organization Science, 13(5), 567-582.

Vanhove, A. J., Herian, M. N., Perez, A. L. U., Harms, P. D., \& Lester, P. B. (2016). Can resilience be developed at work? A meta-analytic review of resilience-building programme effectiveness. Journal of Occupational and Organizational Psychology, 89(2), 278-307.

Vogus, T. J., \& Sutcliffe, K. M. (2007). Organizational resilience: Towards a theory and research agenda. 2007 IEEE International Conference on Systems, Man, and Cybernetics, SMC 2007 (pp. 3418-3422). [4414160] (Conference Proceedings: IEEE International Conference on Systems, Man and Cybernetics).

Walker, B., Holling, C. S., Carpenter, S. R., \& Kinzig, A. (2004). Resilience, adaptability and transformability in social-ecological systems. Ecology and Society, 9(2), 1-9.

Walker, B., \& Salt, D. (2006). Resilience thinking: Sustaining ecosystems and people in a changing world. Island Press.

Weick, K. E., \& Sutcliffe, K. M. (2001). Managing the unexpected: Assuring high performance in an age of complexity. Jossey-Bass.

Weick, K. E., Sutcliffe, K. M., \& Obstfeld, D. (1999). Organizing for high reliability: Processes of collective mindfulness. In R. I. Sutton \& B. M. Staw (Eds.), Research in organizational behavior (Vol. 21, pp. 81-123).

Westrum, R. (2006). A typology of resilience situations. In E. Hollnagel, D. D. Woods, \& N. Leveson (Eds.), Resilience engineering: Concepts and precepts (pp. 55-66). Ashgate Publishing Company. 
Williams, T. A., Gruber, D. A., Sutcliffe, K. M., Shepherd, D. A., \& Zhao, E. Y. (2017). Organizational response to adversity: Fusing crisis management and resilience research streams. Academy of Management Annals, 11(2), 733-769. Woods, D. D. (2019). Essentials of resilience, revisited. In M. Ruth \& S. Goessling-Reisemann (Eds.), Handbook on resilience of socio-technical systems (pp. 52-65). Edward Elgar Publishing.

Yin, R. K. (2009 [1984]). Case study research. Sage Publications.

Zolli, A. (2012). Resilience: Why things bounce back. Simon \& Schuster.

Open Access This chapter is licensed under the terms of the Creative Commons Attribution 4.0 International License (http://creativecommons.org/licenses/ by $/ 4.0 /)$, which permits use, sharing, adaptation, distribution and reproduction in any medium or format, as long as you give appropriate credit to the original author(s) and the source, provide a link to the Creative Commons license and indicate if changes were made.

The images or other third party material in this chapter are included in the chapter's Creative Commons license, unless indicated otherwise in a credit line to the material. If material is not included in the chapter's Creative Commons license and your intended use is not permitted by statutory regulation or exceeds the permitted use, you will need to obtain permission directly from the copyright holder.

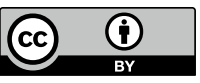

